\title{
Outpatient ertapenem therapy in an ESBL-high- prevalence area: an efficacy, safety, and cost study
}

This article was published in the following Dove Press journal: Infection and Drug Resistance

\author{
Arturo Ortiz-Álvarez' \\ Mónica A Delgado-Ramírez' \\ Montserrat Cuevas-Zúñiga' \\ Teresa Hernández-Carrera' \\ David Moncada Barrón ${ }^{2}$ \\ Daniel Aguilar Zapata' \\ Rafael R Valdez Vázquez' \\ Juan Pablo \\ Ramírez-Hinojosa' \\ Ana Patricia \\ Rodríguez-Zulueta' \\ 'Department of Infectious Disease, \\ Hospital General Dr. Manuel GEA \\ González, Mexico City, Mexico; \\ 2Microbiology Laboratory, Hospital \\ General Dr. Manuel GEA González, \\ Mexico City, Mexico
}

Correspondence: Ana Patricia

Rodríguez-Zulueta

Department of Infectious Disease,

Hospital General Dr. Manuel GEA

González, Calzada de Tlalpan 4800.

CP 14080, Mexico City, Mexico

Email rozu76@hotmail.com
Introduction: Outpatient parenteral antimicrobial therapy is a safe, effective, and convenient way of administering antimicrobials for a wide variety of infections. So far there are no reports on the efficacy of outpatient antimicrobial therapy in Mexico. Our objective was to determine the outcomes, safety, and cost of outpatient ertapenem therapy (OET) in our hospital.

Patients and methods: A case series of 99 patients that received intravenous OET was conducted. The primary outcomes were clinical cure, relapse, and recurrence of infection.

Results: Of the 99 patients who received OET the most common diagnosis was urinary tract infection in 56\%. Extended-spectrum- $\beta$-lactamase-producing Enterobacteriaceae caused $67 \%$ of infections in our population. Ninety-seven percent of the patients were cured at the completion of OET. One patient presented relapse 12 days after the end of OET; two patients presented recurrence, one with skin and soft tissue infection and one with pyelonephritis at days 35 and 34, respectively, after the end of OET. Three patients were readmitted after OET, one with an episode of phlebitis, one with recurrence, and one with relapse. A case of non-Clostridium difficile-associated diarrhea was observed. The intravascular line complications observed during OET were phlebitis in two patients.

Conclusion: In our hospital, the OET was found to be effective, safe, and cost-saving when compared to inpatient care.

Keywords: OPAT, ESBL, ertapenem

\section{Introduction}

The prevalence of drug-resistant microorganisms is growing worldwide, ${ }^{1}$ and in our hospital ESBL-producing Escherichia coli (ESBL-EC) causes 71.4\% of acute pyelonephritis episodes. ${ }^{2}$ Ertapenem is an exceptional antibiotic given as once-daily dosing, and its broad spectrum of activity makes it suitable for outpatient antimicrobial therapy (OPAT). ${ }^{3}$ The early hospital discharge of patients after an OPAT program is noteworthy for several reasons, mainly because of reduced risk of health care-related infections and cost-saving. ${ }^{4-6}$

The Hospital General Dr Manuel GEA González is a secondary health care center with 220 beds in Mexico City, and started the OPAT program in 2014. The program is led by the Infectious Diseases (ID) department and includes patients with no oral options of antimicrobial therapy and without other reason for hospitalization than intravenous (IV) antimicrobial therapy. The experience of OPAT in Mexico is scarce. Thus, clinical outcomes, safety, and cost of outpatient ertapenem therapy (OET) in our hospital were described.

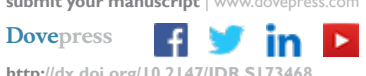




\section{Patients and methods}

The OPAT program began in our hospital in January 2014, only during the morning.

A case series was conducted. One hundred and thirtyseven eligible patients attended the OPAT program from January 28 to December 28, 2014, and 99 patients received IV ertapenem. Inclusion criteria were as follows: 1) adult patients that received OET in the study period, 2) patients receiving ertapenem during hospitalization with an early discharge to the OPAT clinic and those who initiated ertapenem in the ID office, and 3) patients that had an infection caused by ESBL-E with culture result without susceptibility to trimethoprim/sulfamethoxazole or quinolone or received empiric treatment because of the increased risk of ESBL-E.

Medical records, OPAT questionnaire, laboratory results, and radiologic studies were reviewed. Identification of bacteria and antimicrobial susceptibilities were done with Vitek2 (bioMérieux; Durham, NC, USA). The breakpoints were defined according to the guidelines of the Clinical and Laboratory Standards Institute in 2012. High risk for infection due to ESBL-E was determined if the patient had one or more of the following risk factors at the time of hospital admission: previous use of antibiotics, previous hospitalization or urinary tract catheterization (all during the 3 preceding months), transfer from another health care facility, or failure of initial antimicrobial empiric therapy. ${ }^{7-10}$

The primary outcomes were clinical cure, relapse, and recurrence of infection; ertapenem side effects and complications of IV therapy were also registered. Clinical cure was defined as resolution of signs and symptoms of infection and improvement of acute phase reactants (ie, white blood cell count, C-reactive protein, erythrocyte sedimentation rate, platelets count) and/or radiology studies at the end of OET. Subsequent infections were classified as relapse if symptoms returned within 30 days after the end of OET, or recurrent if the interval was more than 30 days. Diagnosis of infection, treatment duration, ertapenem side effects, and venous line complications were defined and acknowledged by an ID specialist.

A comparison of costs was also made as a secondary objective. For this, 20 individuals of the present study were randomly selected with uncomplicated pyelonephritis treated with ertapenem during their hospitalization and as outpatients in the OPAT program after an early discharge (called the OET Group). The IET Group was established with the first 20 patients of 2013 who received ertapenem exclusively in the hospital, identified from the hospital database with the diagnosis of discharge of urinary tract infection (UTI) from an unspecified site (code ICD-10 N39.0). Both groups were classified by the socioeconomic status (SS), implemented as routine in our hospital (1.0.1 1.0.2.07. code). The SS is divided in three levels, SS1, SS2, SS3. The bed-day cost of beds are divided into three levels \$21.45 USD for SS1, \$33.35 USD for SS2, and \$58.57 USD for SS3 respectively.

The expenses of hospitalization of the IET group were compared to those of the OET group (costs of hospitalization plus OET). Hospitalization comprises inpatient hospital stay and expenses incurred during the stay, for instance medical treatment, X-rays, and blood work. The bed-day cost, for instance, was taken from the fees of our institution.

Descriptive statistical analyses were performed on all study variables. Stata software, version 11.0 (StataCorp LLC, College Station, TX, USA), was used. This study was approved by the ethics and research committee of Hospital Dr. Manuel GEA Gonzalez, and all patients signed informed consent.

\section{Results}

\section{Baseline population characteristics}

The mean age of the population was 48 years $(\mathrm{SD} \pm 17)$ and $62 \%$ of the patients were female. Type 2 diabetes was the most frequent comorbidity (39\%). Other baseline characteristics are described in Table 1.

The most frequent type of infection was UTI in 56\%; of these, pyelonephritis represented $42 \%$ of the diagnosis overall $(n=99)$. The mean time from onset of symptoms to attention at our hospital was 33 days, either at the emergency department or ID outpatient clinic. Fifty-one patients of the total $(51 \%)$ received antimicrobials before attention in our hospital; the most frequent antimicrobial was ciprofloxacin in 23 patients $(60 \%$ of whom had UTI), followed by cephalosporin of first, second, and third generation $(25 \%$ of whom had UTI).

Table I Baseline characteristics of the 99 patients with OET

\begin{tabular}{|l|l|}
\hline Characteristics & N (\% or SD) \\
\hline Female & $6 I(62)$ \\
\hline Mean age (years) & $48 \pm 17$ \\
\hline Diabetes mellitus & $39(39)$ \\
\hline Arterial systemic hypertension & $19(19)$ \\
\hline Liver disease & $5(5)$ \\
\hline Human immunodeficiency virus infection & $2(2)$ \\
\hline Immunosuppressive therapy & $3(3)$ \\
\hline Glomerular filtration rate $<60 \mathrm{~mL} /$ min & $3(3)$ \\
\hline Obesity & $17(17)$ \\
\hline Surgery in the preceding 3 months & $25(25)$ \\
\hline Hospitalization in the preceding 3 months & $45(45)$ \\
\hline
\end{tabular}

Abbreviation: OET, outpatient ertapenem therapy. 
Eighty-eight patients required hospital admission, and after hospital discharge, they were placed on OET. Eleven patients were treated with ertapenem entirely as outpatients because of their diagnosis (chronic osteomyelitis and cystitis for example). Of the 88 admitted patients, $61 \%$ received another antimicrobial therapy prior to ertapenem, and their hospital length-of-stay was 10 days on average ( $\mathrm{SD} \pm 8$ ), with a mean of 8 doses of ertapenem ( $\mathrm{SD} \pm 6$ ). The number of days since hospital admission to the beginning of ertapenem therapy was 4 in all patients; 44 patients (88\%) with UTI were started on ertapenem during the first 72 hours of admission, as empiric therapy or guided by microbiologic results.

The mean duration of complete ertapenem therapy (inpatient plus outpatient days) was 15 days $(\mathrm{SD} \pm 9)$ in the total population (Table 2). At the OPAT clinic ( $\mathrm{n}=99$ ), the number of ertapenem doses was 9 on average ( $\mathrm{SD} \pm 6$ ), and $94 \%$ of the patients received it through a periopheral line and $6 \%$ through central line. None of the patients required a change of antibiotic during follow-up.

Regarding microbiological data (Table 3), urine cultures were obtained in $93 \%$ of patients with UTI, $59 \%$ of which were positive for ESBL-EC. Blood cultures were obtained from 55 patients overall (56\%), of whom $34 \%$ showed ESBL-EC (2 skin and soft tisue infections [SSTI], 2 catheter-related bacteremias and 15 UTI); 1 patient had bacteremia due to ESBL-producing Salmonella spp. secondary to pyelonephritis.

\section{Outcomes}

The overall cure rate was $97 \%$ (Table 2). A patient with renal abscess presented relapse at 12 days after the end of OET. Two patients presented recurrence, one with SSTI and one with pyelonephritis at day 35 and 34 days, respectively, both secondary to ESBL-EC. The patient with recurrent SSTI had cirrhosis (Child C) and died due to secondary bacteremia caused by ESBL-EC (the patient refused hospitalization).

Two patients required admission after OET (one relapse and one recurrence), and they received ertapenem during hospitalization. Another patient was admitted from OET to treat phlebitis with IV vancomycin. The adverse events associated with ertapenem therapy were a case of diarrhea at the end of OET (C. difficile infection was ruled out) and two cases of phlebitis related to the intravascular line.

Two patients with HIV infection received OET, one for an abdominal abscess; he had an HIV viral load of 2,231 copies $/ \mathrm{mL}$ and $417 \mathrm{CD} 4+$ cells $/ \mu \mathrm{L}(28 \%)$, and an other due to chronic prostatitis caused by Morganella morganii, who had HIV viral load of $<40$ copies $/ \mathrm{mL}$ and $528 \mathrm{CD} 4+$ cells/ $\mu \mathrm{L}(25 \%)$. OET was also administered to four pregnant patients, three of them with pyelonephritis and one with pelvic inflammatory disease. All of these patients were cured of the infection without complications due to OPAT.

Table 3 Microbiological data

\begin{tabular}{|c|c|c|c|}
\hline Samples & $\mathbf{N}$ & Microorganism & n (\%) \\
\hline \multirow{2}{*}{$\begin{array}{l}\text { Urine } \\
\text { culture }\end{array}$} & \multirow[t]{2}{*}{49} & ESBL-producing E. coli & $29(59)$ \\
\hline & & None & $20(4 I)$ \\
\hline \multirow{3}{*}{$\begin{array}{l}\text { Blood } \\
\text { culture }^{\mathrm{b}}\end{array}$} & \multirow[t]{3}{*}{55} & ESBL-producing E. coli & $19(34)$ \\
\hline & & $\begin{array}{l}\text { ESBL-producing } \\
\text { Salmonella }\end{array}$ & I (2) \\
\hline & & None & $35(64)$ \\
\hline \multirow{3}{*}{$\begin{array}{l}\text { Abdominal } \\
\text { abscess }\end{array}$} & \multirow[t]{3}{*}{18} & ESBL-producing E. coli & $14(78)$ \\
\hline & & Citrobacter freundii & $\mathrm{I}(5)$ \\
\hline & & None & $3(17)$ \\
\hline
\end{tabular}

Notes: aPatients with urinary tract infection (pyelonephritis, renal abscess and cystitis), btotal population.

Abbreviations: ESBL, extended-spectrum- $\beta$-lactamase-eliminar producing Enterobacteriaceae; SSTI, skin and soft tissue infection; UTI, urinary tract infection.

Table 2 Clinical outcomes of patients with OET

\begin{tabular}{|c|c|c|c|c|c|c|c|}
\hline $\begin{array}{l}\text { Type of } \\
\text { infection }\end{array}$ & $\mathbf{N}$ & $\begin{array}{l}\text { In-hospital length- } \\
\text { of-stay plus OET } \\
\text { days (mean } \pm \text { SD) }\end{array}$ & $\begin{array}{l}\text { OET days } \\
\text { (mean } \pm \text { SD) }\end{array}$ & Cure (\%) & $\begin{array}{l}\text { Readmission } \\
\text { after OET }\end{array}$ & $\begin{array}{l}\text { Relapse or } \\
\text { recurrence }\end{array}$ & Phlebitis \\
\hline UTI & 55 & $14 \pm 9$ & $7 \pm 6$ & 96 & 2 & 2 & $\mathrm{I}$ \\
\hline $\begin{array}{l}\text { Abdominal } \\
\text { abscess }\end{array}$ & 21 & $15 \pm 10$ & $8 \pm 6$ & 100 & 0 & 0 & 0 \\
\hline SSTI & 9 & $13 \pm 9$ & $6 \pm 5$ & 89 & 0 & 1 & 0 \\
\hline $\mathrm{JBI}$ & 7 & $42 \pm 10$ & $25 \pm 6$ & 100 & $\mathrm{I}$ & 0 & $\mathrm{I}$ \\
\hline GTI & 4 & $13 \pm 8$ & $10 \pm 6$ & 100 & 0 & 0 & 0 \\
\hline CR-BSI & 3 & $14 \pm 8$ & $10 \pm 5$ & 100 & 0 & 0 & 0 \\
\hline Total & 99 & $15 \pm 9$ & $9 \pm 6$ & 97 & 3 & 3 & 2 \\
\hline
\end{tabular}

Abbreviations: CR-BSI, catheter-related bloodstream infection; OET, outpatient ertapenem therapy; GTI, genital tract infection; JBI, joint and bone infection; SSTI, skin and soft tissue infection; UTI, urinary tract infection. 


\section{Cost analysis}

During the study period, OPAT saved 863 bed days in the 99 patients with OET. Forty patients were classified as SS1, 57 patients as SS2, and 2 patients as SS3. Considering the bed-day cost, the OPAT program saved $\$ 7,936.5$ USD for SS1 patients ( 370 bed-days), \$16,008 USD for SS2 patients (480 bed-days), and \$758 USD for SS3 patients (13 beddays), which altogether resulted in a considerable saving in hospitalisation costs ( $\$ 24,703.5$ USD).

The difference in the cost of medical therapy for an uncomplicated pyelonephritis event (without renal abscess or septic shock) is shown in Table 4; one of the patients in the EIT group with SS3 was excluded from the analysis because there was no way of matching it. The total average cost of treatment for an SS1 subject was \$273 USD versus \$1,031.5 USD for the OET and EIT groups, respectively (3.8 times more expensive for the EIT group). For an SS2 subject the average cost was $\$ 490.7$ USD versus $\$ 1,300$ USD for the OET and EIT groups, respectively (2.7 times more expensive for the EIT group).

\section{Discussion}

Ertapenem is increasingly used in the outpatient setting, as well as in other institutions in our center, after hospitalization to treat many infections. ${ }^{11,12}$ OPAT reduces the incidence of hospital-acquired infections by reducing the length-ofhospital stay and exposure to multidrug-resistant organisms that require more expensive and prolonged treatment. ${ }^{11,16,18-20}$

In our series, $97 \%$ of patients were cured, just like Qureshi et $\mathrm{al}^{13}$ and Chapman et $\mathrm{al}^{16}$ reported in their series. In other series, the readmission of patients reported was around $6.3 \%$ over a period of 2 years; however, in our series only $3 \%$ of the patients required readmission.

The OPAT programs reduce the financial burden of health services; ${ }^{6,16,21,22}$ our OPAT program is an inexpensive choice for patients with infections that require parenteral antimicrobial with no option of oral treatment; ${ }^{15}$ this was corroborated by the comparative analysis of IET vs. OET, which showed higher cost of in-hospital up to 3.8 times. Furthermore, some of our patients continued their daily activities, including working, while receiving OET.

Table 4 Comparison of mean cost of treatment in patients with uncomplicated pyelonephritis

\begin{tabular}{|l|l|l|l|}
\hline $\begin{array}{l}\text { Socioeconomic } \\
\text { status }\end{array}$ & OET & IET & $\boldsymbol{P}$ \\
\cline { 1 - 1 } I & $\$ 273.1(n=7)$ & $\$ 1,032.05(n=9)$ & 0.002 \\
\hline 2 & $\$ 490.7(n=13)$ & $\$ 1,300(n=10)$ & \\
\hline
\end{tabular}

Notes: Results based on mean cost of hospitalization at SS I and 2.

Abbreviations: IET, inpatient ertapenem therapy; OET, outpatient ertapenem therapy.
In this study, UTI was the most frequent diagnosis, and this is probably explained by the high prevalence of type 2 diabetes, as described by Park et al. ${ }^{13}$ The majority of our patients with UTI had received previous treatment, mainly with quinolones and cephalosporin prescribed by primary care physicians, not following the national guidelines ${ }^{14}$ that specify that quinolones are not the first choice of treatment for complicated or repetitive UTI and that urine culture is essential to guide treatment.

In our series, we did not detect carbapenem-resistant organisms unlike other series that reported carbapenemresistant Enterobacteriaceae prevalence up to $10.9 \% .{ }^{17}$

Two patients had phlebitis, similar to that reported by Barr et $\mathrm{al}^{5}$ who described 5-50 events per 1,000 patients with thrombosis, "mechanical" or "chemical" phlebitis. Previous reports of OPAT show an association with $C$. difficile infection ( 0.5 cases per 1,000 patients) ${ }^{11}$ in our study one patient developed diarrhea, but $C$. difficile infection was ruled out.

The OPAT program allowed us to improve hospital surveillance of antimicrobial use by creating a network in real time (via cell phone application) between the pharmacovigilance unit and the ID department, which validates the prescription of broad-spectrum antimicrobials from all services of our institution, such as carbapenems, glycopeptides, oxazolidinones, antifungals (echinocandins and liposomal amphotericin B; Figure 1). This close communication between the patient's consultant and the infectious diseases department medical staff (who have valuable information from the microbiology laboratory) is practical and allows the infectious diseases team to know which patients require their assessment, and thus, we recommend this method of antimicrobial stewardship to be performed in other institutions.

Our study is limited by its observational nature and relatively small number of patients from a single national reference center, with $85 \%$ (84/99) of patients living in Mexico City, 26\% (22/84) of whom lived in the same suburb where our hospital is located. Besides, we did not quantify the number of patients that did not accept the OPAT because of difficulties such as travelling to the hospital every day to receive OPAT (long travel distance, lack of social support network, and increased costs of transportation).

One limitation of our study and the OPAT program was that at our facility during 2014 the OPAT program did not function on the weekends; this represents trouble for drug administration safety and an extra cost for patients, who hired a nurse during weekends and after-office hours. For the cost analysis, the study did not take into account the cost paid by the patient for transport from home to hospital and back; 


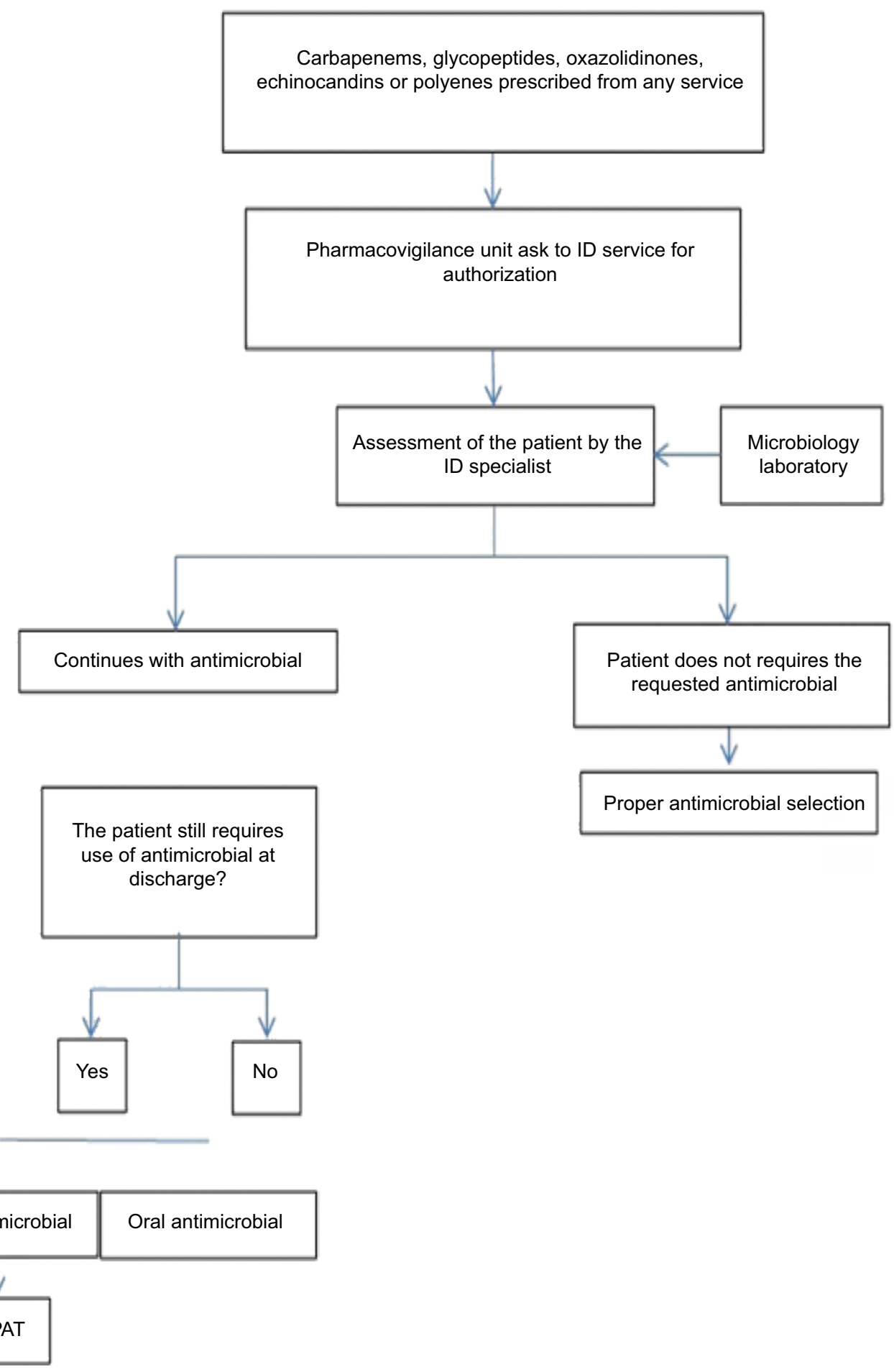

Figure I Antimicrobial stewardship at Dr Manuel Gea Gonzalez Hospital.

Notes: After the categorization of an infectious syndrome by the patient's consultant physician (emergency, internal medicine, surgery, orthopedics, gynecology, and obstetrics), the infectious disease team prescribe antibiotic according to the diagnosis and local resistance. When any service requires an antimicrobial, the pharmacovigilance unit works together with ID and microbiology departments to assess, discuss, and decide if the patient requires the antimicrobial prescribed. After the assessment, the route of the antimicrobial treatment follows this flowchart. At the end, if the patient still needs antimicrobial treatment then they will be transferred to the OPAT.

Abbreviations: ID, Infectious Diseases; OPAT, outpatient antimicrobial treatment.

however, most of the patients lived in the same area where the hospital was located.

To our knowledge, this is the first study of this kind conducted in Mexico, and future studies need to be conducted that include all patients undergoing OPAT at our center, and the results need to assess satisfaction and accessibility, integral costs, and its impact on nosocomial infections. Compared with low-income countries in Latin America, a study 
group in Brazil has reported that OPAT therapy did have a reduced cost compared with the hospitalization expenses, and they included patients with osteomyelitis - this is a group of patients that usually requires antimicrobial for a long period of time. In our study, most of the included patients had complicated UTI or intra-abdominal infections that did not require antimicrobial therapy for long periods. ${ }^{23}$ Usually for osteomyelitis, we try to prescribe antimicrobials with high penetration to bone plus oral medication like minocycline, doxycycline, or fosfomycin.

In Mexico, the health care system is divided in three major ways, the own insurance health care, the social security health care, and the public service (dedicated to people that do not have the first two). Our hospital is part of the public service system, which means that most of the cost is absorbed by the government. In that regard, OPAT is effective in the setting of a patient who needs IV antimicrobial treatment in low-income countries.

\section{Conclusion}

This study demonstrates that OET in selected patients is safe, effective, leads to few complications, and results in lower costs when compared to inpatient care, especially at our institution.

\section{Acknowledgment}

We would like to thank the team that conducted the program (ID specialists, microbiology laboratory, and the OPAT staff) for their effort every day with the patients. Data were generated by the authors as part of their routine work. Authors were not funded for data collection.

\section{Disclosure}

Dr Ana Patricia Rodriguez Zulueta is a speaker for $\mathrm{MSD}^{\circledR}$, Stendhal Pharma ${ }^{\circledR}$, and Pfizer ${ }^{\circledR}$. Dr Daniel Aguilar Zapata is speaker for Stendhal Pharma ${ }^{\circledR}$, Pfizer ${ }^{\circledR}$, and Gilead ${ }^{\circledR}$. Dr Rafael Valdez Vazquez is an employee of Pfizer. The authors received no economic support for this work. The authors report no other conflicts of interest in this work.

\section{References}

1. Hawser SP, Bouchillon SK, Hoban DJ, Badal RE. In vitro susceptibilities of aerobic and facultative anaerobic Gram-negative bacilli from patients with intra-abdominal infections worldwide from 2005-2007: results from the SMART study. Int J Antimicrob Agents. 2009;34(6):585-588.

2. Cornejo-Dávila V, Palmeros-Rodríguez MA, Uberetagoyena-Tello de Meneses I, et al. Management of complicated urinary tract infections in a referral center in Mexico. Int Urol Nephrol. 2015;47(2):229-233.
3. Zhou J, Sulaiman Z, Llorin RM. Pharmacokinetics of ertapenem in outpatients with complicated urinary tract infections. J Antimicrob Chemother. 2014:2517-2521.

4. Tice AD, Rehm SJ, Dalovisio JR. Practice Guidelines for Outpatient Parenteral Antimicrobial Therapy. 2004;38:1651-1672.

5. Barr DA, Semple L, Seaton RA. Outpatient parenteral antimicrobial therapy (OPAT) in a teaching hospital-based practice: a retrospective cohort study describing experience and evolution over 10 years. Int $J$ Antimicrob Agents. 2012;39(5):407-413.

6. Chapman AL, Seaton RA, Cooper MA, et al. Good practice recommendations for outpatient parenteral antimicrobial therapy (OPAT) in adults in the UK: a consensus statement. J Antimicrob Chemother. 2012;67(5):1053-1062.

7. Volkow F. [Outpatient management manual for intravenous therapy for patients with cancer] Manual del Manejo Ambulatorio de la Terapia Intravenosa para el Enfermo con Cáncer. Noriega Editores UTEHA. 2001:1-135. Spanish.

8. Doi Y, Park YS, Rivera JI, et al. Community-associated extendedspectrum $\beta$-lactamase-producing Escherichia coli infection in the United States. Clin Infect Dis. 2013;56(5):641-648.

9. Azap OK, Arslan H, Serefhanoğlu K, et al. Risk factors for extendedspectrum beta-lactamase positivity in uropathogenic Escherichia coli isolated from community-acquired urinary tract infections. Clin Microbiol Infect. 2010;16(2):147-151.

10. Laupland KB, Church DL, Vidakovich J, Mucenski M, Pitout JD. Community-onset extended-spectrum beta-lactamase (ESBL) producing Escherichia coli: importance of international travel. $J$ Infect. 2008;57:441-448.

11. Seaton RA, Barr DA. Outpatient parenteral antibiotic therapy: Principles and practice. Eur J Intern Med. 2013;24(7):617-623.

12. Qureshi ZA, Syed A, Doi Y. Safety and efficacy of long-term outpatient ertapenem therapy. Antimicrob Agents Chemother. 2014;58(6): 3437-3440.

13. Park SH, Choi SM, Lee DG, et al. Impact of extended-spectrum $\beta$-lactamase production on treatment outcomes of acute pyelonephritis caused by escherichia coli in patients without health careassociated risk factors. Antimicrob Agents Chemother. 2015;59(4): 1962-1968.

14. Guía de Práctica Clínica. [Diagnosis and Treatment of Pyelonephritis Acute not Complicated in the Adult. Mexico: Ministry of Health] Diagnóstico y Tratamiento de la Pielonefritis Aguda no Complicada en el Adulto. México: Secretaría de Salud; 2014. Available from: http:// www.cenetec.salud.gob.mx/contenidos/gpc/catalogoMaestroGPC.html. Spanish. Accessed December 1, 2014.

15. Park SH, Choi SM, Chang YK, et al. The efficacy of non-carbapenem antibiotics for the treatment of community-onset acute pyelonephritis due to extended-spectrum $\beta$-lactamase-producing Escherichia coli. $J$ Antimicrob Chemother. 2014;69(10):2848-2856.

16. Chapman AL, Dixon S, Andrews D, Lillie PJ, Bazaz R, Patchett JD. Clinical efficacy and cost-effectiveness of outpatient parenteral antibiotic therapy (OPAT): a UK perspective. J Antimicrob Chemother. 2009;64(6):1316-1324.

17. Paterson DL, Ko WC, von Gottberg A, et al. Antibiotic therapy for Klebsiella pneumoniae bacteremia: implications of production of extended-spectrum beta-lactamases. Clin Infect Dis. 2004;39(1):31-37.

18. Lane MA, Marschall J, Beekmann SE, et al. Outpatient parenteral antimicrobial therapy practices among adult infectious disease physicians. Infect Control Hosp Epidemiol. 2014;35(7):839-844.

19. Muldoon EG, Snydman DR, Penland EC, Allison GM. Are we ready for an outpatient parenteral antimicrobial therapy bundle? A critical appraisal of the evidence. Clin Infect Dis. 2013;57(3):419-424.

20. Gilchrist M, Seaton RA. Outpatient parenteral antimicrobial therapy and antimicrobial stewardship: challenges and checklists. J Antimicrob Chemother. 2015;70(4):965-970. 
21. Dryden M, Saeed K, Townsend R, et al. Antibiotic stewardship and early discharge from hospital: impact of a structured approach to antimicrobial management. J Antimicrob Chemother. 2012;67(9):2289-2296.

22. Nathwani D, Tice A. Ambulatory antimicrobial use: the value of an outcomes registry. J Antimicrob Chemother. 2002;49(1):149-154.
23. Oliveira PR, Carvalho VC, Cimerman S, Lima ALM, Diretrizes Brasileiras para Terapia Antimicrobiana Parenteral Ambulatorial group. Recommendations for outpatient parenteral antimicrobial therapy in Brazil. Braz J Infect Dis. 2017;21(6):648-655.

\section{Publish your work in this journal}

Infection and Drug Resistance is an international, peer-reviewed openaccess journal that focuses on the optimal treatment of infection (bacterial, fungal and viral) and the development and institution of preventive strategies to minimize the development and spread of resistance. The journal is specifically concerned with the epidemiology of antibiotic

\section{Dovepress}

resistance and the mechanisms of resistance development and diffusion in both hospitals and the community. The manuscript management system is completely online and includes a very quick and fair peerreview system, which is all easy to use. Visit http://www.dovepress.com/ testimonials.php to read real quotes from published authors.

Submit your manuscript here: https://www.dovepress.com/infection-and-drug-resistance-journal 